\title{
Are all patients subject to the same follow-up after type A dissection repair?
}

\author{
Charles M. Wojnarski, MD, MS
}

\author{
From the University Hospitals Cleveland Medical Center, Case Western Reserve University, Cleveland, Ohio. \\ Disclosures: Author has nothing to disclose with regard to commercial support. \\ Received for publication May 8, 2018; revisions received May 8, 2018; accepted for publication May 9, 2018; \\ available ahead of print June 21, 2018. \\ Address for reprints: Charles M. Wojnarski, MD, MS, University Hospitals Cleveland Medical Center, 11100 Eu- \\ clid Ave, Cleveland, OH 44106 (E-mail: charles.wojnarski@uhhospitals.org). \\ J Thorac Cardiovasc Surg 2018;156:1786 \\ $0022-5223 / \$ 36.00$ \\ Copyright (c) 2018 by The American Association for Thoracic Surgery \\ https://doi.org/10.1016/j.jtcvs.2018.05.023
}

An attempt to understand the underlying variability in the presentation of disease underpins every research endeavor in medicine. To study the variability of individuals in a population, we must establish variables that differentiate patients from one another. Over time, we can develop a similar distribution of variables that can be used to group patients of a similar phenotype; that is, patients with the same disease who have similar physical manifestations of disease. ${ }^{1}$ Finally, understanding the influence of these findings on clinical outcomes guides our ability to tailor our surgical approach to individual patients.

Leone and colleagues ${ }^{2}$ describe the histopathologic specimens of 158 patients who underwent surgical repair of type A dissection at a single institution over a 13-year period starting in 2000. The authors classify the specimen as either degenerative or mixed degenerativeatherosclerotic and compare baseline characteristics and several clinical outcomes through a 6-year follow-up. They use a multivariable regression to adjust for several key baseline differences between groups.

After adjusting for differences between groups, they found no difference in mortality or aorta-related events through their midterm follow-up. They did note a small difference in nonaorta cardiovascular events through 6 years. Another interesting finding in their Table E2 $2^{2}$ was that atherosclerotic changes were found at almost all intramural hematomas compared with only half of type A dissections (91\% vs $53 \% ; P=.023)$.

The study is limited by the small number of patients in each group. This lack of power impedes our ability to understand the true clinical implications of the classification system imposed by the Society for Cardiovascular Pathology in 2015 and the Association for European Cardiovascular Pathology in 2016. Once differences between groups were adjusted for with a multivariable model, the statistical significance of the difference in outcomes between the 2 groups becomes marginal.

Despite the lack of tangible clinical implications of the study, it does reiterate that patients with atherosclerotic

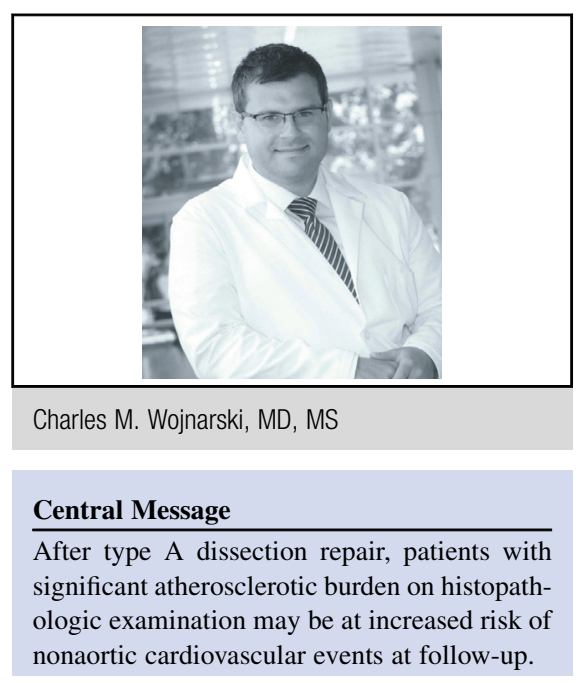

See Article page 1776.

ascending aortic changes who have type A dissection are at increased risk for nonaortic cardiovascular events. In emergency settings, these patients often do not undergo coronary angiography. Several studies have shown a lower incidence of coronary artery disease in patients with thoracic aortic disease compared with those with more distal aortic pathology. ${ }^{3,4}$ However, the incidence of coronary disease in older patients with type A dissection occurring in the background of significant atherosclerosis is not trivial ( $23 \%$ in the current series).

After recovering from type A dissection repair, patients with mixed degenerative-atherosclerotic pathology should undergo a thorough cardiovascular risk assessment and age-appropriate screening because they are at higher risk of nonaortic complications compared with their counterparts with degenerative etiology for type A dissection.

\section{References}

1. Geiler-Samerotte K, Bauer C, Li S, Ziv N, Gresham D, Siegal ML, et al. The details in the distributions: why and how to study phenotypic variability. Curr Opin Biotechnol. 2013;24:752-9.

2. Leone $\mathrm{O}$, Pacini D, Foà A, Corsini A, Agostini V, Corti B, et al. Redefining the histopathologic profile of acute aortic syndromes: clinical and prognostic implications. J Thorac Cardiovasc Surg. 2018;156:1776-85.

3. Islamoglu F, Atay Y, Can L, Kara E, Ozbaran M, Yuksel M, et al. Diagnosis and treatment of concomitant aortic and coronary disease: a retrospective study and brief review. Tex Heart Inst J. 1999;26:182-8.

4. Agmon Y, Khandheria BK, Meissner I, Schwartz GL, Sicks JD, Fouht AJ, et al. Is aortic dilatation an atherosclerosis-related process? Clinical, laboratory, and transesophageal echocardiographic correlates of thoracic aortic dimensions in the population with implications for thoracic aortic aneurysm formation. J Am Coll Cardiol. 2003;42:1076-83. 